\title{
Potencial do lodo doméstico da ETE como adubação orgânica na cultura do crambe
}

O crambe (Crambe abyssinica Hochst), pertencente à família Brassicaceae cujas sementes contém cerca de 35-60\% de óleo, surge como opção para produção do óleo vegetal. A sua precocidade são as maiores vantagens da planta, que floresce aos 35 dias e pode ser colhida aos 90 dias após a emergência, podendo atingir produtividade média de $1000-1800 \mathrm{~kg}$ ha-1. Nesse trabalho avaliou-se o desenvolvimento do crambe submetido a doses crescentes de lodo doméstico da ETE. Os tratamentos foram constituídos de: $0 ; 4 ; 8 ; 16$ e $32 \mathrm{Mg}$ há-1. Cada unidade experimental foi constituída por vasos contendo $2 \mathrm{~kg}$ de solo, com quatro repetições. O solo utilizado foi o Latossolo Vermelho Amarelo Distrófico. Foram avaliados: número de folhas, altura da planta, matéria seca da biomassa vegetal e determinação do conteúdo de nitrogênio na planta total. Os resultados foram submetidos a análise de variância (ANOVA), seguida da análise de regressão em função das doses, utilizando o programa estatístico SAEG. Os resultados de análise de crescimento indicaram que com o aumento das doses do lodo doméstico a planta respondeu melhor em termos de altura e número de folhas. Para peso seco, a planta obteve um melhor desenvolvimento com a dose de $32 \mathrm{Mg}$ há-1. Em relação ao conteúdo de nitrogênio, o maior conteúdo de nitrogênio foi observado com a dose $32 \mathrm{Mg}$ ha-1.

Palavras-chave: Lodo doméstico; Crambe; Composto Orgânico; Analise de crescimento.

\section{Potential of ETE's domestic sludge as organic fertilization in crambe culture}

\begin{abstract}
Crambe (Crambe abyssinica Hochst), belonging to the Brassicaceae family whose seeds contain about $35-60 \%$ of oil, appears as an option for the production of vegetable oil. Its precocity is the main advantage of the plant, which blooms at 35 days and can be harvested at 90 days after emergence, reaching average productivity of $1000-1800 \mathrm{~kg}$ ha-1. This work evaluated the development of crambe submitted to increasing doses of domestic sludge from TEE. The treatments consisted of: 0; 4; 8; 16 and $32 \mathrm{Mg}$ ha-1. Each experimental unit consisted of vessels containing $2 \mathrm{~kg}$ of soil, with four replicates. The soil used was the Dystrophic Yellow Red Latosol. Leaf number, plant height, dry matter of the plant biomass and determination of the nitrogen content in the total plant were evaluated. The results were submitted to analysis of variance (ANOVA), followed by the regression analysis according to the doses, using the statistical program SAEG. The results of growth analysis indicated that with increasing doses of domestic sludge the plant responded better in terms of height and number of leaves. For dry weight, the plant had a better development with a dose of $32 \mathrm{Mg}$ ha-1. In relation to the nitrogen content, the highest nitrogen content was observed with the $32 \mathrm{Mg}$ ha-1 dose.
\end{abstract}

Keywords: Domestic sludge; Cramb; Organic compôs; Growth analysis.

Topic: Engenharia Agrícola

Reviewed anonymously in the process of blind peer.
Received: 08/06/2021

Approved: 24/06/2021
Aline do Amaral Leite (10)

Universidade Federal de Lavras

http://lattes.cnpq.br/5933329415145484

http://orcid.org/0000-0002-0813-4631

alineleite000@gmail.com

Joseane Oliveira da Silva

Instituto Federal da Bahia, Brasil

http://lattes.cnpq.br/2924129863852832

http://orcid.org/0000-0002-5927-4095

joseaneoliveiras@yahoo.com.br

Sara Moreno Pereira Lacerda (iD)

Universidade Estadual do Sudoeste da Bahia, Brasil

http://lattes.cnpq.br/4575166715919352

http://orcid.org/0000-0002-1610-8732

saramp16@gmail.com

\author{
Thamires Oliveira da Silva (iD) \\ Faculdade Sudoeste, Brasil \\ http://lattes.cnpq.br/5986851617646015 \\ http://orcid.org/0000-0002-4213-5793 \\ thamiires.makarena@gmail.com \\ Felizardo Adenilson Rocha (D) \\ Instituto Federal da Bahia, Brasil \\ http://lattes.cnpq.br/1581393124834413 \\ http://orcid.org/0000-0001-6410-5176 \\ felizardoar@hotmail.com \\ Lorena Lima Ferraz (iD \\ Universidade Estadual de Santa Cruz, Brasil \\ http://lattes.cnpq.br/2679970266851969 \\ http://orcid.org/0000-0003-3997-1069 \\ lore-ferraz@hotmail.com
}

\section{Referencing this:}

LEITE, A. A.; SILVA, J. O.; LACERDA, S. M. P.; SILVA, T. O.; ROCHA, F. A.; FERRAZ, L. L.. Potencial do lodo doméstico da ETE como adubação orgânica na cultura do crambe. Revista Ibero Americana de Ciências Ambientais, v.12, n.6, p.108-117, 2021. DOI:

http://doi.org/10.6008/CBPC2179-6858.2021.006.0009 


\section{INTRODUÇÃO}

O crambe (Crambe abyssinica Hochst) é uma oleaginosa que tem se destacado como fonte para a produção de biodiesel. Esse potencial é devido ao fato de fácil adaptabilidade a solos eutróficos, além de ser tolerante a estiagens e geadas (REGINATO et al., 2013). Os grãos de crambe produzem óleo de excelente qualidade industrial e, e o maior atrativo é o baixo custo (FERREIRA et al., 2013). Entretanto, para alcançar boas produtividades deve-se conhecer as suas demandas nutricionais e manter em níveis adequados os atributos referentes à fertilidade do solo, visto que não há ainda recomendações especificas para essa cultura (ROGERIO et al., 2012; KNIGHTS, 2002).

Em função das necessidades por práticas agrícolas sustentáveis que minimizem as perdas e ocasionem melhoria da eficiência de uso de nutriente, a fertilização do solo promovida por resíduos orgânicos se torna uma alternativa viável e com bons resultados. Desses resíduos, o lodo de esgoto doméstico pode ser utilizado como um substituinte, ainda que parcial., dos fertilizantes químicos, contribuindo para uma melhoria da fertilidade do solo (CAMARGO et al., 2000).

O lodo de esgoto doméstico é o resíduo produzido em maior quantidade em estações de tratamento de esgoto doméstico (ETEs), sendo caracterizado como um material rico em matérias orgânicas e nutrientes (GARCIA, 2010). Esse material é gerado no processo de tratamento do efluente e deve receber um tratamento adequado visando a sua estabilização para que posteriormente seja destinado de forma correta. No entanto, devido à dificuldade e o alto custo desse processo, muitas vezes acaba sendo negligenciado pelas ETEs depositando-o de forma incorreta ou sem tratamento adequado, o que acaba gerando um passivo ambiental comprometendo a qualidade dos ecossistemas envolvidos (PEDROZA et al., 2010).

O lodo doméstico depois de tratado atua como composto orgânico fornecendo macro e micronutrientes ao solo, disponibilizando-os gradativamente através de mineralização (TAMANINI et al., 2004). Dentre os nutrientes encontrados em maiores concentrações no lodo de esgoto estão o nitrogênio, elemento de grande exigência pelas plantas, e o fósforo. Em relação às concentrações de micronutrientes observa-se uma quantidade maior de cobre, zinco e manganês (COSTA et al., 2011).

Por conta de suas características químicas, se torna possível a utilização do lodo de esgoto como um adubo orgânico, incrementando a produção agrícola e promovendo uma melhoria na qualidade e na fertilidade dos solos. Além disso, o seu emprego na agricultura promove também uma redução de custos de seu tratamento e disposição final (BONINI et al., 2015; PEDROZA et al., 2010). No entanto, seu uso na agricultura deve atender as exigências propostas pela CONAMA 375, relacionadas a qualidade do material., sua estabilização, desinfecção e outas restrições de uso (BRASIL, 2006), bem como atender as diretrizes gerais segundo a Lei Federal no 12.305 de 2 de agosto de 2010, a qual constitui a política nacional de resíduos sólidos (BRASIL, 2010).

O uso do lodo no solo pode provocar mudanças tanto nas características físicas como nas características químicas do mesmo. Aplicações sucessivas promoveram uma maior estabilidade de agregados, com consequente melhoria na retenção e infiltração de água, crescimento de raízes e diminuição 
da densidade do solo (MARIA et al., 2007). Além disso, a sua aplicação no solo ocasiona uma diminuição do pH e um aumento nos teores de matéria orgânica, nitrogênio total., fósforo, potássio, sódio, cálcio e magnésio no cultivo de milho e feijoeiro (NASCIMENTO et al., 2004).

Assim, destaca-se a importância de estudos que avaliem a viabilidade de incorporação do lodo doméstico da ETE no cultivo agrícola, que possivelmente possibilitará uma destinação mais adequada e ainda promoverá a incorporação dos nutrientes do solo utilizado para desenvolvimento das culturas. Diante do exposto, o presente trabalho teve como objetivo avaliar os efeitos da aplicação de doses crescentes de lodo de esgoto doméstico no crescimento e desenvolvimento da cultura do Crambe.

\section{MATERIAIS E MÉTODOS}

O experimento foi realizado em casa de vegetação localizada no Instituto Federal da Bahia - IFBA, utilizando amostras de um Latossolo Vermelho Amarelo distrófico, coletado na profundidade de 0,0 a 0,20 m. O solo foi seco ao ar, destorroado, peneirado, homogeneizado e submetido à análise química (Tabela 1) (EMBRAPA, 1997).

Tabela 1: Resultado da análise química do solo utilizado no experimento antes da implantação.

\begin{tabular}{|c|c|}
\hline Profundidade $0,0-0,20 \mathrm{~m}$ & Valor \\
\hline $\mathrm{pH}\left(\mathrm{H}_{2} \mathrm{O}\right)$ & 5,2 \\
\hline $\mathrm{Ca}\left(\mathrm{cmol}_{\mathrm{c}} / \mathrm{dm}^{3}\right)$ & 0,2 \\
\hline $\mathrm{Mg}\left(\mathrm{cmol}_{\mathrm{c}} / \mathrm{dm}^{3}\right)$ & 0,5 \\
\hline $\mathrm{K}\left(\mathrm{cmol}_{\mathrm{c}} / \mathrm{dm}^{3}\right)$ & 0,02 \\
\hline $\mathrm{Al}\left(\mathrm{cmol}_{\mathrm{c}} / \mathrm{dm}^{3}\right)$ & 0,4 \\
\hline $\mathrm{H}\left(\mathrm{cmol}_{\mathrm{c}} / \mathrm{dm}^{3}\right)$ & 3,4 \\
\hline $\left.\mathrm{SB}\left(\mathrm{cmol}_{\mathrm{c}} / \mathrm{dm}^{3}\right)\right)$ & 0,7 \\
\hline $\mathrm{T}\left(\mathrm{cmol}_{\mathrm{c}} / \mathrm{dm}^{3}\right)$ & 1,1 \\
\hline $\mathrm{t}\left(\mathrm{cmol}_{\mathrm{c}} / \mathrm{dm}^{3}\right)$ & 4,5 \\
\hline V (\%) & 16 \\
\hline m (\%) & 36 \\
\hline $\mathrm{MO}\left(\mathrm{mg} / \mathrm{dm}^{3}\right)$ & 12 \\
\hline
\end{tabular}

SB: Soma de bases, T: capacidade de troca de cátions potencial., t: capacidade de troca de cátions efetiva, V\%: saturação por base, m: índice de saturação por alumínio, PST: porcentagem de saturação por sódio, MO: Matéria orgânica.

O lodo de esgoto doméstico utilizado no experimento foi produzido na embasa (Empresa Baiana de Águas e Saneamento), estação de tratamento de esgoto da cidade de Vitória da Conquista, Bahia. O material foi seco, destorroado e logo após, as amostras passaram por análise química. Os resultados dessas análises são apresentados na tabela 2.

Tabela 2: Resultado da análise química do lodo da ETE utilizado no experimento.

\begin{tabular}{|c|c|}
\hline Característica & Valor \\
\hline $\mathrm{pH}\left(\mathrm{H}_{2} \mathrm{O}\right)$ & 6,1 \\
\hline $\mathrm{Ca}\left(\mathrm{g} \mathrm{kg}^{-1}\right)$ & 20 \\
\hline $\mathrm{Mg}\left(\mathrm{g} \mathrm{kg}^{-1}\right)$ & 3 \\
\hline $\mathrm{K}_{2} \mathrm{O}$ Sol. $\left(\mathrm{g} \mathrm{kg}^{-1}\right)$ & 0,8 \\
\hline $\mathrm{K}_{2} \mathrm{O}$ Total $\left(\mathrm{g} \mathrm{kg}^{-1}\right)$ & 10 \\
\hline $\mathrm{N}$ - total $\left(\mathrm{g} \mathrm{kg}^{-1}\right)$ & 26 \\
\hline $\mathrm{P}_{2} \mathrm{O}_{5}\left(\mathrm{~g} \mathrm{~kg}^{-1}\right)$ & 8 \\
\hline$C\left(\mathrm{~g} \mathrm{~kg}^{-1}\right)$ & 318,7 \\
\hline $\mathrm{MO}\left(\mathrm{g} \mathrm{kg}^{-1}\right)$ & 589,6 \\
\hline $\mathrm{Fe}\left(\mathrm{mg} \mathrm{kg}^{-1}\right)$ & 33269 \\
\hline $\mathrm{Zn}\left(\mathrm{mg} \mathrm{kg}^{-1}\right)$ & 1617 \\
\hline $\mathrm{Cu}\left(\mathrm{mg} \mathrm{kg}^{-1}\right)$ & 266 \\
\hline
\end{tabular}


$\mathrm{Mn}\left(\mathrm{mg} \mathrm{kg}^{-1}\right)$

$\mathrm{Ca}$ - Cálcio; $\mathrm{Mg}$ - Magnésio; $\mathrm{K}_{2} \mathrm{O}$ - Oxido de potássio; $\mathrm{N}$ - Nitrogênio; $\mathrm{P}_{2} \mathrm{O}_{5}$ - Pentóxido de fosforo $\mathrm{C}-$ Carbono; $\mathrm{MO}$ Matéria orgânica; Fe - Ferro; Zn - Zinco; Cu - Cobre; Mn - Manganês.

O delineamento experimental foi inteiramente casualizado (DIC) com doses crescentes de lodo de esgoto doméstico constituindo os seguintes tratamentos: 0; 4; 8; 16 e 32 Mgha-1. Cada unidade experimental constituiu vasos contendo $2 \mathrm{~kg}$ de solo, com quatro repetições, totalizando 20 unidades experimentais. Para a correção da acidez, o solo foi incubado com carbonato de cálcio, durante um período de 30 dias visando elevar a saturação por bases (V\%) para 60\%.

Foram utilizadas sementes da cultura do crambe, FMS Brilhante, com ciclo médio de 90 dias. As sementes foram colocadas para germinar e após 10 dias as plântulas de crambe foram transplantadas para os vasos definitivos, permanecendo uma planta por vaso. A irrigação das plantas foi feita periodicamente, mantendo o solo numa capacidade de campo de 70\%. Para a análise de crescimento do crambe, a cada 15 dias após o transplante foram analisadas as seguintes variáveis: altura das plantas (AP) e número de folhas (NF). As leituras da altura de planta foram feitas medindo-se a distância entre o colo e a extremidade superior da haste principal da planta, sendo realizadas utilizando-se de régua graduada e a unidade dada em centímetros $(\mathrm{cm})$. Aos 90 dias após a emergência aproximadamente, as plantas foram colhidas, separandose parte aérea (folha, caule e grão) e raiz para determinação da massa fresca. Em seguida, este material foi posto para secar em estufa a $60^{\circ} \mathrm{C}$ até atingir massa constante para determinação da massa seca.

A determinação da concentração de nitrogênio também foi feita com base na metodologia proposta pela EMBRAPA (1997) pelo método de Destilação - Titulação de Kjeldahl. Na digestão foi feita a decomposição do tecido vegetal., sendo realizada através da solubilização com ácido sulfúrico (H2SO4) e peroxido de hidrogênio (H2O2). O amônio ( $\mathrm{NH} 4+$ +) produzido na digestão com H2SO4 foi destilado em meio fortemente alcalino. $\mathrm{O} \mathrm{NH4+} \mathrm{condensado} \mathrm{foi} \mathrm{coletado} \mathrm{na} \mathrm{solução} \mathrm{de} \mathrm{H3BO3} \mathrm{e} \mathrm{titulado} \mathrm{com} \mathrm{a} \mathrm{solução} \mathrm{de} \mathrm{ácido} \mathrm{clorídrico}$ $(\mathrm{HCl})$.

A determinação do teor de nitrogênio $(\mathrm{g} / \mathrm{kg})$ foi realizada a partir da diferença dos volumes gasto na titulação com $\mathrm{HCl}$ no branco subtraído pelo volume gasto na titulação com $\mathrm{HCl}$ gasto, com o valor resultante multiplicado pelo fator de correção 1,4. A determinação do conteúdo de nitrogênio em $\mathrm{mg} /$ planta foi determinada pela multiplicação do peso seco pelo teor de nitrogênio. Os dados foram submetidos à análise de variância (ANOVA) seguida da análise de regressão em função das doses lodo doméstico proveniente da ETE utilizando-se o programa estatístico SAEG - Statistical Analysis System (GOMES, 1992).

\section{RESULTADOS E DISCUSSÃO}

Na tabela 3 é representada a análise de variância para a altura da planta e número de folhas da planta do crambe. Os resultados obtidos para o crescimento do crambe submetida a diferentes doses do lodo doméstico indicaram que tanto as doses, a época e a interação dose x época apresentaram uma significância estatística de $1 \%$, sendo assim, a época influenciou nas doses estudadas. O coeficiente de variação apresentou-se baixo para altura de planta de acordo com o esperado para um experimento conduzido em 
casa de vegetação. Porém, para a variável número de folhas, esse valor foi superior, pois, à medida que o crambe se aproxima do fim de seu período fisiológico, 90 a 100 dias após o transplante, as folhas se tornam amareladas e caem (DESAI, 2004).

Tabela 1: Quadrado médio da análise de variância (ANOVA) para altura da planta do crambe $(A P, \mathrm{~cm})$ e número de folhas do crambe (NF, cm) submetida a diferentes doses do lodo doméstico da ETE.

\begin{tabular}{llll}
\hline FV & GL & Quadrado Médio \\
\hline Total & \multicolumn{3}{l}{ NF } \\
\hline Total redução & 139 & & \\
Trat & 37 & $4485,925^{* *}$ & $137,1654^{* *}$ \\
Época (Ep) & 4 & $1831,416^{* *}$ & $37,63214^{*}$ \\
Repetição & 6 & $25110,31^{* *}$ & $674,0452^{* *}$ \\
Trat x Ep & 3 & $344,9129^{*}$ & $15,15 n s$ \\
Resíduo & 24 & $289,8735^{* *}$ & $34,78631^{* *}$ \\
\hline CV (\%) & 102 & 121,2047 & 13,05197 \\
\hline
\end{tabular}

*;**; ns: Siginificativo a 5\%, significativo a $1 \%$ e não significativo, respectivamente, pelo teste $\mathrm{F}$.

Os resultados referentes às análises de crescimento para as variáveis alturas da planta e número de folhas são representados nas figuras 1 e 2 .

Até o momento não há relatos de trabalhos que avaliaram o crescimento da cultura do crambe através da utilização de lodo de esgoto doméstico como fonte de nutrientes. Entretanto, já é bem conhecido o uso de fontes alternativas à fertilizantes químicos para promover a fertilização para essa cultura (PRATES et al., 2014; FREDIANI et al., 2012).

Em relação à altura da planta, com o avanço da época de amostragem, houve uma resposta significativa com o aumento das doses do lodo de esgoto doméstico. Durante todo o ciclo da cultura os tratamentos mantiveram-se crescentes, no entanto, é possível notar que para as doses de $0 \mathrm{Mg} / \mathrm{ha}$ e $8 \mathrm{Mg} / \mathrm{ha}$ apresentaram crescimento mais lento, enquanto que, os tratamentos de $16 \mathrm{Mg} / \mathrm{ha}$ e $32 \mathrm{Mg} / \mathrm{ha}$ apresentaram um crescimento mais rápido na mesma época estudada, ou seja, a planta se desenvolveu melhor em termos de altura quando aumentaram-se as doses do lodo doméstico, obtendo melhor resposta. A partir de 75 dias todos os tratamentos mantiveram crescimento uniforme até o final do ciclo da planta.

Diversos trabalhos relatam a utilização do lodo de esgoto em culturas anuais, demonstrando ser uma fonte bastante promissora de adubação. Ao cultivar mamona com doses crescentes de lodo de esgoto Lima et al. (2015), notaram um crescimento proporcional aos 40 e 80 dias após a germinação nas variáveis altura da planta e no número de folhas para todos os tratamentos. No entanto, não foi observado efeito residual., podendo estar relacionado à intensa extração de nutrientes pela mamona no primeiro cultivo, além da lixiviação de nutrientes. Já para Barbosa et al. (2007) a utilização de doses de lodo de esgoto apresentou efeito residual na produtividade de milho safrinha, proporcionada pela melhoria do crescimento da cultura, resultando em maior incremento de matéria seca.

Em relação ao número de folhas, aos 15 dias após o transplante (DAT) o mesmo ainda era uniforme, ou seja, ainda sem efeito das doses do lodo de esgoto. Aos 30 DAT percebeu-se um aumento no número de folhas em função do aumento das doses do lodo de esgoto e por fim, dos 75 aos 90 dias todos os tratamentos chegaram ao fim do período fisiológico com uma diminuição do número de folhas. 

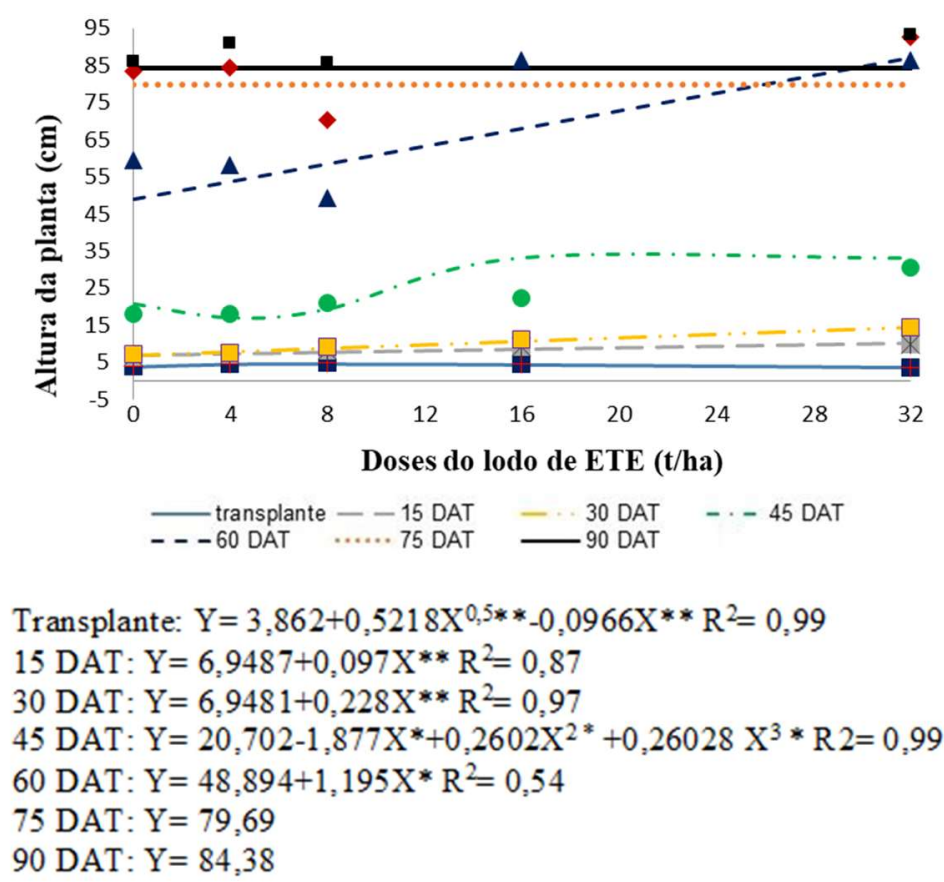

Figura 1: Altura da planta do crambe em função das doses do composto orgânico (lodo de esgoto da ETE).

Esse resultado está de acordo com Lobo et al. (2012), no qual., o nitrogênio proveniente do lodo de esgoto proporcionou um incremento na altura e número de folhas na cultura do girassol. Isso acontece, pois, o nitrogênio é extraído pela cultura em grandes quantidades e não sendo possível ocorrer um efeito residual direto no solo. Já em estudos realizados por Zuba Junior et al. (2011), o crescimento inicial da mamona adubada com doses de lodo doméstico e doses de silicato de cálcio e magnésio, não proporcionaram aumentos significativos no variável número de folhas. Esse fato pode ser explicado pela intensa mineralização da matéria orgânica no crescimento inicial da mamona.

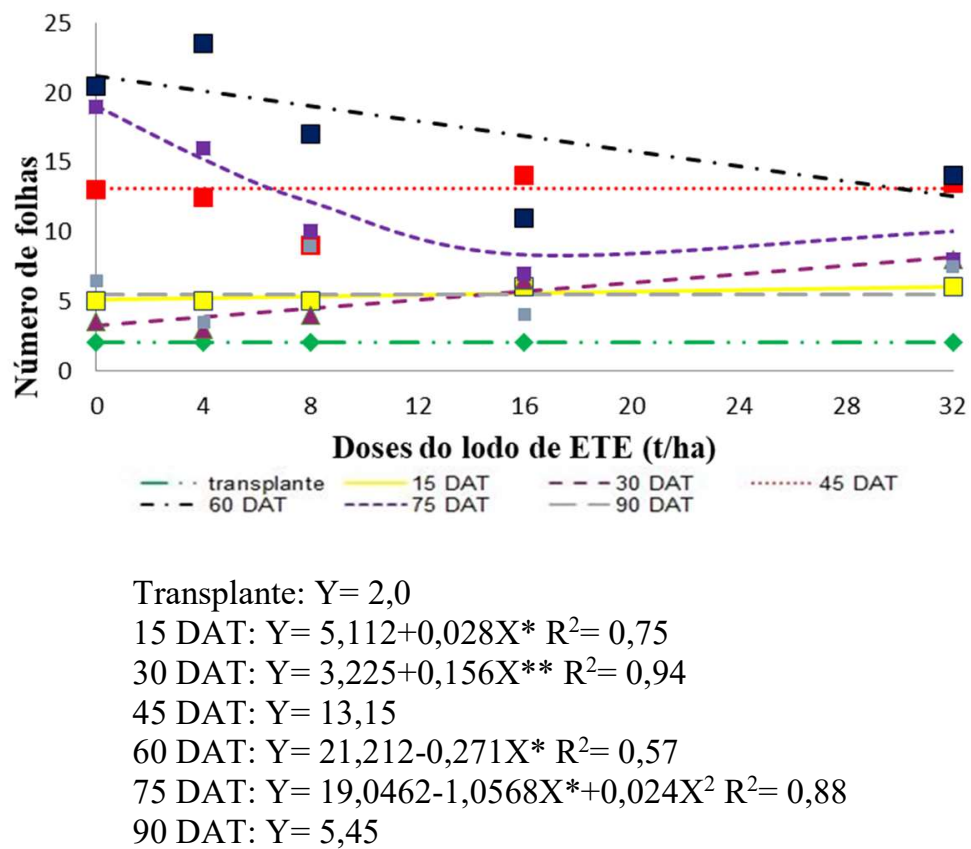

Figura 2: Número de folhas de planta do crambe em função das doses do composto orgânico (lodo doméstico ETE).

Na tabela 4 é representada a análise de variância para peso seco da planta do crambe submetida a diferentes doses de lodo doméstico. 
Tabela 2: Quadrado médio da análise de variância (ANOVA) para peso seco do caule (PSC, g/planta), peso seco da folha (PSF, g/planta), peso seco do grão (PSG, g/planta), peso seco da parte aérea (PSPA, g/planta), peso seco da raiz (PSR, g/planta), peso seco total da planta (PSPT, g/planta) submetida a diferentes doses do lodo doméstico da ETE.

\begin{tabular}{llllllll}
\hline \multicolumn{7}{l}{ QUADRADO MÉDIO } & \multicolumn{2}{l}{} \\
\hline FV & GL & PSC & PSF & PSG & PSR & PSPA & PSPT \\
\hline Trat & 4 & $1,50528^{* *}$ & $0,012200^{\text {ns }}$ & $1,081101^{* *}$ & $8,961768^{* *}$ & $5,650680^{* *}$ & $28,66519^{* *}$ \\
Repetição & 3 & $0,06954^{\text {ns }}$ & $0,0321966^{\text {ns }}$ & $0,01448^{\text {ns }}$ & $0,171267^{*}$ & $0,0312867^{\text {ns }}$ & $0,3355467^{\text {ns }}$ \\
Resíduo & 12 & 0,03082 & 0,03674 & 0,01157 & 0,02197 & 0,10013 & 0,12476 \\
\hline CV (\%) & & 9,27 & 58,917 & 14,267 & 9,642 & 10,642 & 7,831 \\
\hline
\end{tabular}

$*^{* *} ; *$; ns: Siginificativo a $1 \%$, Significativo a $5 \%$ e não significativo, respectivamente, pelo teste $\mathrm{F}$.

$\mathrm{Na}$ análise de variância para o peso seco, com exceção da variável PSF, todas as variáveis foram altamente significativas ao nível de $1 \%$ de probabilidade pelo teste $\mathrm{F}$. Em relação ao coeficiente de variação, as variáveis apresentaram valores condizentes com experimentos conduzidos em casa de vegetação onde o PSPT apresentou o menor coeficiente de variação em relação aos demais. Como a planta do crambe perde todas as suas folhas quando se aproxima do fim de seu período fisiológico (70 DAT) o coeficiente de variação de PSF apresentou-se alto justificando esse comportamento.

Na Figura 3 é representada a produção de peso seco em função das doses crescentes de lodo de esgoto doméstico.

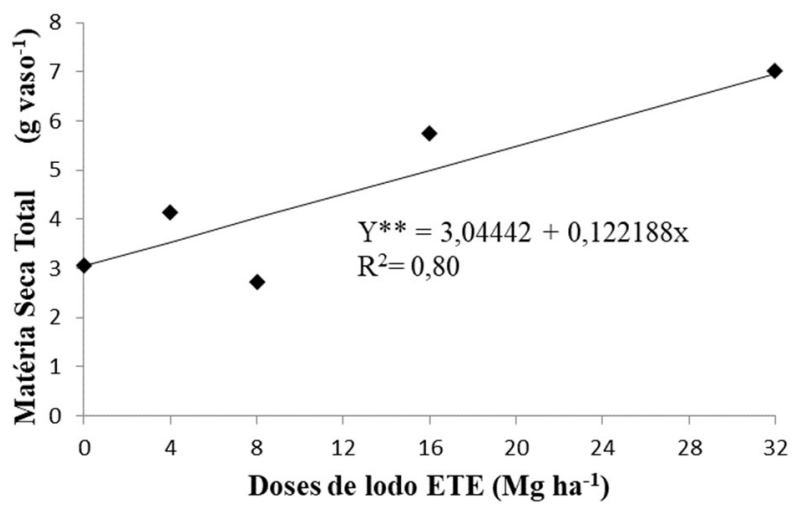

Figura 3: Matéria seca da planta total em função das doses crescentes do lodo doméstico da ETE.

A produção de matéria seca da planta do crambe em função das doses crescentes de lodo de esgoto doméstico apresentou comportamento linear, ou seja, com o aumento das doses aplicadas foi alcançada maior produção de matéria seca. Além disso, o maior incremento de peso foi encontrado para o tratamento de maior dose (32 Mg ha-1), com um aumento de $228 \%$ em relação ao tratamento controle. Para Caldeira et al. (2013), a utilização de doses de lodo doméstico associadas com doses de vermiculita proporcionaram um maior incremento de peso seco para as mudas de Eucalyptus grandis. As maiores médias foram encontradas para a variável raiz com adubação de $80 \%$ de lodo doméstico e $20 \%$ de vermiculita.

Já para Faria et al. (2013) na produção de mudas de Senna alata, utilizando diferentes doses do lodo doméstico misturadas com fibra de coco, e tratamentos apenas com substrato comercial., observou um maior incremento de peso seco no tratamento com maior dose do lodo e a menor média obtida foi observada no tratamento composto apenas por substrato comercial. Resultados semelhantes também foram encontrados por Maas et al. (2010), onde as doses crescentes do lodo doméstico influenciaram diretamente na produção de peso seco do Timburi. Portanto, infere-se que, em decorrência do aumento das doses de 
lodo doméstico, houve aumento no aproveitamento dos nutrientes pela planta e consequente aumento na produção. Na Tabela 5 é representada a análise de variância do conteúdo de nitrogênio em função das diferentes doses de lodo doméstico.

Tabela 5: Quadrado médio da análise de variância (ANOVA) para o conteúdo de nitrogênio no caule (CNC, $\mathrm{mg} / \mathrm{planta}$ ), o conteúdo de nitrogênio na folha (CNF, mg/planta), o conteúdo de nitrogênio no grão (CNG, $\mathrm{mg} / \mathrm{planta}$ ), o conteúdo de nitrogênio na parte aérea (CNPA, mg/planta), o conteúdo de nitrogênio na raiz (CNR, g/planta), o conteúdo de nitrogênio total da planta (CNPT, $\mathrm{mg} /$ planta) submetida a diferentes doses do lodo doméstico da ETE.

\begin{tabular}{llllllll}
\hline \multicolumn{7}{l}{ QUADRADO MÉDIO } & \multicolumn{2}{l}{ CNR } & CNPA & CNPT \\
\hline FV & GL & CNC & CNF & CNG & CNR & $5,66892^{* *}$ & $23,42018^{* *}$ \\
Trat & 2 & $1,44905^{* *}$ & $0,35393^{*}$ & $0,339033^{* *}$ & $6,04875^{* *}$ & $0,070339^{\text {ns }}$ \\
Repetição & 4 & $0,000474^{\text {ns }}$ & $0,037737^{\text {ns }}$ & $0,0045409^{\text {ns }}$ & $0,9983484^{\text {ns }}$ & $0,051723^{\text {ns }}$ & 0,1158833 \\
Resíduo & 8 & 0,2636144 & 0,041011 & 0,036289 & 0,006352 & 0,095316 & 0,168 \\
\hline CV (\%) & & 18,748 & 49,268 & 14,267 & 8,681 & 18,168 & 13,006 \\
\hline
\end{tabular}

**; *; ns: Siginificativo a $1 \%$, significativo a $5 \%$ e não significativo, respectivamente, pelo teste $\mathrm{F}$.

Na análise de variância do conteúdo de nitrogênio, a variável CNF foi significativa

$\mathrm{Na}$ análise de variância do conteúdo de nitrogênio, somente a variável CNF foi significativa ao nível ao nível de $5 \%$, no entanto, as variáveis CNC, CNG, CNR, CNPA e CNPT foram significativas ao nível de $1 \%$ de probabilidade pelo teste $\mathrm{F}$. Em relação ao coeficiente de variação, as variáveis apresentaram valores baixos, onde o menor valor foi encontrado na variável CNR e o maior valor atribuído pela variável CNF, como também observado para peso seco da folha. Na Figura 4 é representado o conteúdo de nitrogênio em função das doses crescentes de lodo de esgoto doméstico.

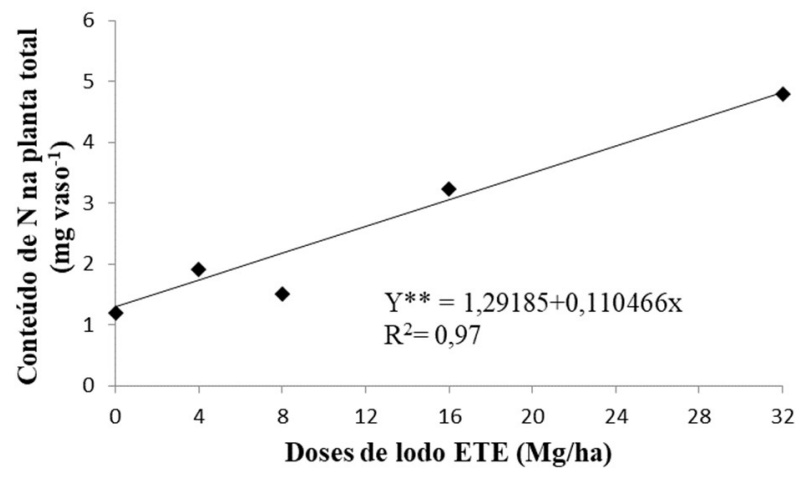

Figura 4: Conteúdo de nitrogênio total em função das doses crescentes do lodo doméstico da ETE.

A avaliação do conteúdo de nitrogênio indica que o aumento das doses de lodo doméstico, aplicado ao solo, proporcionaram efeitos significativos na absorção desse elemento pela cultura. Esses efeitos ocorreram de forma diretamente proporcional., sendo possível o estabelecimento de uma regressão linear, com aumento da absorção de $\mathrm{N}$ em função do aumento das doses. Além disso, o conteúdo de nitrogênio total da planta apresentou um aumento de 400 \% em relação ao tratamento controle. Na avaliação dos efeitos da aplicação de lodo de esgoto e a sua viabilidade como fornecedor de $\mathrm{N}$, comparado a fontes minerais sobre a produtividade agroindustriais da cana-de-açúcar, Tasso Júnior et al. (2007) afirmam que o $\mathrm{N}$ fornecido pelo lodo de esgoto é capaz de suprir as necessidades da cultura, resultando em maior produtividade da mesma.

Oliveira et al. (1995), constataram que as parcelas que receberam $20 \mathrm{Mg} \mathrm{ha}^{-1}$ obtiveram efeitos 
significativos de absorção de nitrogênio pela cultura do sorgo. No entanto, fez-se necessário uma complementação de adubação por potássio pela necessidade da cultura. Na produção de milho e feijão preto, Gardioli (2004) observou que a dose de $5 \mathrm{Mg}$ há $^{-1}$ calculada em função do nitrogênio disponível mostrou-se adequada, sugerindo dessa forma sua utilização para incorporação de nitrogênio no solo para ambas as culturas. Corroborando com resultados de Pires et al. (2015), em que aplicações sucessivas de lodo de esgoto ocasionou um aumento na eficiência de disponibilização de $\mathrm{N}$ a longo prazo, pois o mesmo possibilita aumento relevante de $\mathrm{N}$ mineralizável.

\section{CONCLUSÕES}

O lodo doméstico da ETE proporcionou incremento significativo no número de folhas e na altura da planta de acordo com o avanço da época de amostragem. A dose $32 \mathrm{Mg} / \mathrm{ha}$ apresentou a maior produção de massa seca total da planta. As doses crescentes do lodo doméstico da ETE proporcionaram maior conteúdo de nitrogênio na planta, sendo o melhor resultado observado com a dose de $32 \mathrm{Mg} / \mathrm{ha}$.

\section{REFERÊNCIAS}

BARBOSA, G. M. C.; TAVARES FILHO, J.; BRITO, O. R.; FONSECA, I. C. B.. Efeito residual do lodo de esgoto na produtividade do milho safrinha. R. Bras. Ci. Solo, v.31, p.601-605, 2006.

BONINI, C. S. B.; ALVES, M. C.; MONTANARI, R.. Lodo de esgoto e adubação mineral na recuperação de atributos químicos de solo degradado. Revista Brasileira de Engenharia Agrícola e Ambiental, v.19, n.4, p.388-393, 2015. DOI http://dx.doi.org/10.1590/18071929/agriambi.v19n4p388-393

BRASIL. Ministério do Meio Ambiente. Conselho Nacional de Meio Ambiente. Resolução CONAMA no 375, de 29 de agosto de 2006. Resoluções. Brasília: CONAMA, 2006.

BRASIL. Lei Federal no 12.305/2010. Política Nacional de Resíduos Sólidos. Brasília: DOU, 2010.

CALDEIRA, M.; DELARMELINA, W. M.; PERONI, L.; GONÇALVES, E. O.; SILVA, A. G.. Lodo de esgoto e vermiculita na produção de mudas de eucalipto. Pesquisa Agropecuária Tropical., Goiânia, v.43, n.2, p.155-163, 2013.

CAMARGO, O. A.; BETTIOL, W.. Agricultura: opção animadora para a utilização de lodo de esgoto. 0 Agronômico, Campinas, v.52, n.2-3, p.13-16, 2000.

COSTA, A. F.; COSTA, A. N.. Aspectos químicos e físicos da disposição do lodo de ETE no solo. In: Manual de uso agrícola e disposição do lodo de esgoto para o estado do Espírito Santo. Vitória, 2011.

DESAI, B.. Seeds Handbook: Biology, Production Processing and Storage. 2 ed. New York: Marcel Dekker, 2004.

EMPRAPA. Empresa Brasileira de Pesquisa Agropecuária. Manual de Métodos Empregados em Estudos de Microbiologia de Solos. Brasília: EMBRAPA, 1997.
FARIA, J. C. T.; CALDEIRA, M. V. W.; DELARMELINA, W. M.; LACERDA, L. C.; GONÇALVES, E. O.. Substratos à base de lodo de esgoto na produção de mudas de Senna alata. Com. Sci., Bom Jesus, v.4, n.4, p.342-351, 2013.

FERREIRA, F. M.; SILVA, A. R. B.; POLIZEL, A. C.; SILVA, E. M. B.. Influência dos manejos do solo no desenvolvimento da cultura do crambe. Energ. Agric., Botucatu, v.28, n.3, p.179$184,2013$.

FREDIANE, F. R.; FERNANDES, F. C.. Avaliação de adubação orgânica em crambe. Cultivando o Saber, Cascavel, v.5, n.3, p.7-13, 2012.

GARDIOLI, J.. Rendimento de milho e de feijão preto cultivado em solo acrescido de lodo de esgoto. Sanare. Revista Técnica da Sanepar, Curitiba, v.21, n.21, p.53-58, 2004.

GARCIA, G. O.; GONÇALVES, I. Z.; MADALÃO, J. C.; NAZÁRIO, A. A.; REIS, E. F.. Crescimento de mudas de eucalipto submetidas à aplicação de biossólidos. Revista Ciência Agronômica, v.41, n.1, p.87-94, 2010.

GOMES, J. M.. SAEG 5.0: Sistema de análises estatísticas e genéticas, SAEG. Viçosa: UFV, 1992.

KNIGHTS, E. G.. Crambe: A North Dakota case study. A Report for the Rural Industries Research and Development Corporation. Kingston, 2002.

LIMA, R. L. S.; SEVERINO, L. S.; SILVA, M. I. L.; LOPES, F. F. M.; JERONIMO, J. F.; BELTRAO, N. E. M.. Crescimento de mudas de mamoneira em função de adição de doses de biossólido em diferentes composições de substrato. In: CONGRESSO BRASILEIRO DE PLANTAS OLEAGINOSAS, ÓLEOS, GORDURAS E BIODIESEL, 2. Anais. Varginha: UFLA, 2005. p.138-142. 
LOBO, T. F.; FILHO, L. G.; COELHO, H. A.. Efeito da adubação nitrogenada na produtividade do girassol. Científica, Jaboticabal, v.40, n.1, p.59-68, 2012.

MAAS, K. D. B.; MAAS, G. C. B.; TAVARES, L. S.; WEBER, O. L. S.; VALADÃO, F. C. A.. Uso do biossólido na produção de mudas do Timburi (Enterolobium contortisiliquun (Vell.)). In: SIMPÓSIO ITALO-BRASILEIRO DE ENGENHARIA SANITARIA E AMBIENTAL, 10. Anais. Maceió, 2010.

MARIA, I. C.; ANSELMIKOCSSI, M.; DECHEN, S. C. F.. Agregação do solo em área que recebeu lodo de esgoto. Bragantia, v.66, n.2, p.291-298, 2007.

NASCIMENTO, C. W. A.; BARROS, D. A. S.; MELO, E. E. C.; OLIVEIRA, A. B.. Alterações químicas em solos e crescimento de milho e feijoeiro após aplicação de lodo de esgoto. $\mathbf{R}$. Bras. Ci. Solo, v.28, p.385-392, 2004.

OLIVEIRA, F. C.; MARQUES, M. O.; BELLINGIERI, P. A.; PERECIN, D.. Lodo de esgoto como fonte de macronutriente para a cultura do sorgo granífero. Sci. Agric., Piracicaba, v.52, n.2, p.360-367, 1995.

PIRES, A. M. M.; ANDRADE A. C.; SOUZA, N. A. P.; CARMO, J. B.; COSCIONE A. R.; CARVALHO, C. S.. Disponibilidade e mineralização do nitrogênio após aplicações sucessivas de lodo de esgoto no solo, estimadas por meio de incubação anaeróbica. Pesq. Agropec. Bras., Brasília, v.50, n.4, p.333342, 2015.

PEDROZA, M. M.; VIEIRA, G. E. G.; SOUSA, J. F.; PICKLER, A. C.; LEAL., E. R. M.; MILOMEN, C. C.. Produção e tratamento de lodo de esgoto: uma revisão. Revista Liberato, v.11, n.16, p.89-188, 2010.

PRATES, F. B. S.; GENUNCIO, G. C.; FERRARI, A. C.; NASCIMENTO, E. C.; ALVES, G. Z.; PALERMO, D. P.; ZONTA,
E.. Acúmulo de nutrientes e produtividade de crambe em função da fertilização com torta de mamona e serpentinito Nutrient accumulation and productivity of crambe according to fertilization castor bean and. 2014.

REGINATO, P.; SOUZA, C. M. A.; SILVA, C. J.; RAFULL, L. Z. L.. Desempenho agronômico e qualidade de sementes de crambe em diferentes épocas e profundidades de semeadura. Pesq. Agropec. Bras., Brasília, v.48, n.10, p.1410-1413, 2013. DOI: http://doi.org/10.1590/S0100$\underline{204 \times 2013001000013}$

ROGERIO, F.; SANTOS, J. I.; SILVA, T. R. B.; MIGLIAVACCA, R. A.; GOUVEIA, B.; BARBOSA, M. C.. Efeito de doses de fósforo no desenvolvimento da cultura do Crambe. Biosci. J., Uberlândia, v.28, n.1, p.251-255, 2012.

TASSO JÚNIOU, L. C.; MARQUES, M. O.; FRANCO, A.; NOGUEIRA, G. A.; NOBILE, F. O.; CAMILOTTI, F.; SILVA, A. R.. Produtividade e qualidade de cana-de-açúcar cultivada em solo tratado com lodo de esgoto, vinhaça e adubos minerais. Eng. Agríc., Jaboticabal., v.27, n.1, p.276-283, 2007. DOI: http://doi.org/10.1590/S0100-69162007000100022

TAMANINI, C. R.; ANDREOLI, C. V.; MOTTA, A. C. V.; DOETZER, B. H.; PEGORINI, E. S.. Estudo da utilização de altas doses de biossolido na recuperação de área decapada em São José dos Pinhais. In: CONGRESSO BRASILEIRO DE ENGENHARIA SANITÁRIA E AMBIENTAL, 23. Anais. 2004.

ZUBA JUNIOR, G. R.; SAMPAIO, R. A.; SANTOS, G. B.; NASCIMENTO, A. L.; PRATES, F. B.; FERNANDES, L. A.. Metais pesados em milho fertilizado com fosfato natural e composto de lodo de esgoto. Revista Brasileira de Engenharia Agrícola e Ambiental., v.15, n.10, p.1082-1088, 2011.

A CBPC - Companhia Brasileira de Produção Científica (CNPJ: 11.221.422/0001-03) detém os direitos materiais desta publicação. Os direitos referem-se à publicação do trabalho em qualquer parte do mundo, incluindo os direitos às renovações, expansões e disseminações da contribuição, bem como outros direitos subsidiários. Todos os trabalhos publicados eletronicamente poderão posteriormente ser publicados em coletâneas impressas sob coordenação da Sustenere Publishing, da Companhia Brasileira de Produção Científica e seus parceiros autorizados. Os (as) autores (as) preservam os direitos autorais, mas não têm permissão para a publicação da contribuição em outro meio, impresso ou digital, em português ou em tradução. 